\title{
AINDA AS AÇÕES AFIRMATIVAS COMO INSTRUMENTOS À PROMOÇÃO DA IGUALDADE DE GÊNERO NO BRASIL
}

\author{
Ana Carolina Elaine dos Santos Guedes de Castro* \\ Andréa Abrahão Costa**
}

Resumo: Este artigo tem como objetivo analisar os postulados da teoria da Justiça de Nancy Fraser e sua relação com o direito de liberdade e o princípio da igualdade, identificando ações afirmativas para garantir a paridade de gênero. Far-se-á uma síntese da citada teoria, com destaque para a efetivação do reconhecimento e distribuição. Analisar-se-á, sob a perspectiva da Constituição da República de 1988, os princípios da igualdade, liberdade, e da justiça social. Ao final, citar-se-ão as Leis 11.340/06 e 9.504/95 como exemplos de ações afirmativas no contexto da igualdade de gênero.

Palavras-chave: ações afirmativas; reconhecimento; distribuição; gênero; igualdade.

\section{AFFIRMATIVE ACTIONS AS INSTRUMENTS FOR THE PROMOTION OF GENDER EQUALITY IN BRAZIL}

\begin{abstract}
This article aims to analyze the postulates of Nancy Fraser's theory of justice and its relationship with the right of freedom and the principle of equality, identifying affirmative actions to guarantee gender parity. A synthesis of the aforementioned theory will be made, with emphasis on the realization of recognition and distribution. From the perspective of the Constitution of the Republic of 1988, the principles of equality, freedom, and social justice will be examined. In the end, Laws 11.340 / 06 and 9.504 / 95 will be cited as examples of affirmative action in the context of gender equality.
\end{abstract}

Keywords: affirmative actions; recognition; distribution; gender; equality.

\section{INTRODUÇÃO}

O presente artigo tem como objetivo analisar os postulados da Teoria da Justiça de

\footnotetext{
* Doutoranda em Ciência Jurídica pela Universidade do Vale do Itajaí. Advogada e Professora do Curso de Direito da Fesp/PR.

** Doutora em Direito pela Pontifícia Universidade Católica do Paraná. PUC/PR/Université Paris X. Professora Adjunta do curso de Direito da Universidade Federal de Goiás - Regional Goiás.
} 
Nancy Fraser e sua relação com o direito de liberdade e o princípio da igualdade, previstos na Constituição Federal, bem como, identificar algumas ações afirmativas que visam garantir a paridade de gênero.

Para tanto, far-se-á uma breve síntese da Teoria da Justiça de Nancy Fraser, com destaque para a efetivação do reconhecimento e distribuição.

Em um segundo momento, analisar-se-á, sob a perspectiva da Constituição da República de 1988, os Princípios da igualdade, liberdade, e da justiça social, dando enfoque à previsão legal das ações afirmativas.

Ao final, citar-se-ão as Leis 11.340/06 e 9.504/95comoexemplos de ações afirmativas no contexto da igualdade de gênero. Inserida na linha de pesquisa "Principiologia Constitucional e Política Jurídica" o tema proposto possibilitará a “elaboração do Direito com base em interesses legítimos, materialmente eficaz pelos sentimentos da ética, do legítimo, do justo e do útil"1.

Para a investigação do objeto e meio para atingir o objetivo proposto, utilizar-se-á o método dedutivo na fase de investigação da pesquisa, o método cartesiano quanto à coleta de dados; e as técnicas do referente, categoria, conceito operacional, fichamento e da pesquisa bibliográfica ${ }^{2}$.

\section{CONSIDERAÇÕES SOBRE A TEORIA DA JUSTIÇA DE GÊNERO EM NANCY} FRASER $^{3}$

Com o estudo voltado para a análise dos movimentos feministas e das Teorias da Justiça, Nancy FRASER ${ }^{4}$ explica que o feminismo marxista da década de 70, analisava as relações de gênero e de subordinação das Mulheres a partir de uma análise da divisão de classes e do trabalho.

\footnotetext{
${ }^{1}$ MELO, Osvaldo Ferreira de. Fundamentos da política jurídica. Porto Alegre: Antônio Sergio Fabris Editor, 1994. p. 22.

${ }^{2}$ PASOLD, Cesar Luiz. Metodologia da pesquisa jurídica: teoria e prática.14 ed.rev.atual. e amp. Florianópolis: EMais, 2018.

${ }^{3}$ Adota-se a teoria do reconhecimento de Nancy Fraser como norte para indicar as reivindicações feministas por igualdade e justiça. FRASER, Nancy. La política feminista em la era Del reconocimiento: um enfoque bidimensional de la justicia de gênero. Título original: Feminists Politics in the Age os Recognition: a twodimensional approach to gender justice. Traducción: Marta Postigo Asenjo.In: Arenal, 19:2; Julio-deciembre 2012, p. 267- 286.

${ }^{4}$ FRASER, Nancy. La política feminista em la era Del reconocimiento: um enfoque bidimensional de la justicia de gênero. Título original: Feminists Politics in the Age os Recognition: a two-dimensional approach to gender justice. Traducción: Marta Postigo Asenjo.In: Arenal, 19:2; Julio-deciembre 2012, p. 267-286.
} 
Nos anos 90, as teorias feministas partiram para uma abordagem de gênero em que o comportamento e a opressão constituíam resultados de uma construção social, e, que os conflitos se relacionavam, em sua vasta maioria, com a identidade e a representação.

Desta forma, enquanto na década de 70, a desigualdade originava-se da política econômica adotada, na separação entre trabalho produtivo e reprodutivo; duas décadas depois, a desigualdade passou a fundamentar-se em um critério cultural, reconhecendo que as normas de gênero estariam "interconectadas aos padrões culturais de interpretação e valoração que são essenciais para manter o sistema geral de estratificação"5; e, que tais padrões institucionalizados "privilegiam traços associados à masculinidade, enquanto desvaloriza aquilo que se percebe e interpreta como feminino"6.

A construção jurídica influenciada por este modelo submeteu as Mulheres a uma sorte de "subordinação, de status baseada no gênero, que abarca o assédio, abusos sexuais, violência doméstica, coisificação, degradação, privação de direitos e garantias jurídicas da cidadania"7.

Estas formas de injustiça, estariam, portanto, diretamente relacionadas à falta de Reconhecimento.

É sob esta perspectiva que FRASER propõe uma Teoria da Justiça, reunindo, para tanto, uma política de redistribuição e reconhecimento. Ou seja, uma proposta de Política Feminista de Reconhecimento da identidade feminina.

FRASER expõe, ainda, que:

A falta de Reconhecimento se daria quando as instituições sociais regulam a interação social com normas androcêntricas que impedem a paridade, como é o caso do direito penal. Uma política de Reconhecimento teria como função a desinstitucionalização dos padrões masculinos de valor cultural que impedem a Igualdade de

\footnotetext{
${ }^{5}$ FRASER, Nancy.La política feminista em la era Del reconocimiento: um enfoque bidimensional de la justicia de gênero. Título original: Feminists Politics in the Age os Recognition: a two-dimensional approach to gender justice. Traducción: Marta Postigo Asenjo.In: Arenal, 19:2; Julio-deciembre 2012, p. 267-286

6 5FRASER, Nancy.La política feminista em la era Del reconocimiento: um enfoque bidimensional de la justicia de gênero. Título original: Feminists Politics in the Age os Recognition: a two-dimensional approach to gender justice. Traducción: Marta Postigo Asenjo.In: Arenal, 19:2; Julio-deciembre 2012, p. 272

${ }^{7}$ FRASER, Nancy.La política feminista em la era Del reconocimiento: um enfoque bidimensional de la justicia de gênero. Título original: Feminists Politics in the Age os Recognition: a two-dimensional approach to gender justice. Traducción: Marta Postigo Asenjo.In: Arenal, 19:2; Julio-deciembre 2012, p. 273
} 
Gênero e, substituí-los por padrões que a promovam. ${ }^{8}$

Combinar políticas de redistribuição e reconhecimento representaria uma das formas de se promover a igualdade.

Destacam SILVA e WRIGHT que, para se fazer valer a Justiça de Gênero temos:

De pensar nas estratégias implementadas junto aos sistemas e/ou instituições que recebem, constitucionalmente, a responsabilidade para realizar o reconhecimento dos direitos e a distribuição dos serviços e bens materiais ou imateriais entre mulheres e homens ${ }^{9}$.

Indispensável, portanto, analisar, a partir da Constituição da República, os Princípios relacionados ao Reconhecimento e à Distribuição como critérios para realização da Justiça de que propõe Nancy FRASER. Na sequência, abordar-se-á alguns instrumentos de origem constitucional que possam servir de amparo à realização da igualdade de gênero.

\section{IGUALDADE E LIBERDADE COMO DIREITOS FUNDAMENTAIS}

Sob um aspecto histórico, HELLER aponta que os ideais de liberdade e igualdade remontam à antiguidade, sendo sua concepção aprofundada na "consciência europeia através da história da Igreja Cristã" ${ }^{\prime 10}$. Explica, ainda, que liberdade e igualdade, no sentido político-social, foram consideradas direitos "inato[s] ao homem somente a partir do século XVII em que se passou a vigorar o predomínio do direito natural racional, o que influiu em toda a Constituição política"11.

Por sua vez, a convivência harmônica entre a sociedade e Estado é dependente de um conjunto de fatores dentre eles, o de fundamental importância, é o "Estatuto Fundamental" ${ }^{\prime 2}$, que abriga uma série de direitos individuais bem como delimita o poder do

\footnotetext{
${ }^{8}$ FRASER, Nancy.La política feminista em la era Del reconocimiento: um enfoque bidimensional de la justicia de gênero. Título original: Feminists Politics in the Age os Recognition: a two-dimensional approach to gender justice. Traducción: Marta Postigo Asenjo.In: Arenal, 19:2; Julio-deciembre 2012, p. 273

${ }_{9}$ DA SILVA, Salete Maria; WRIGHT, Sonia Jay. Uma reflexão feminista sobre o conceito de justiça de gênero. In: Revista de teorias da justiça, da decisão e da argumentação jurídica. v. 2; n. 1; jan-jun; 2016. p. 14

${ }^{10}$ HELLER, Hermann. Teoria do Estado. Tradução de Lycurgo Gomes da Motta. São Paulo: Mestre Jou,1968. Título original: Staatslehre.p. 148-149

${ }^{11}$ HELLER, Hermann. Teoria do Estado. Tradução de Lycurgo Gomes da Motta. São Paulo: Mestre Jou,1968.

Título original: Staatslehre.p. 148-149

${ }^{12}$ GOULART, Clovis de Souto. Formas e Sistemas de Governo. Porto Alegre/Fpolis: Sérgio Antonio Fabris Editor/CPGD-UFSC, 1995.p.12
} 
Estado.

A Constituição da República Federativa do Brasil de 1988 consagra os Direitos Fundamentais, estabelecendo, dentre outras características, a sua inalienabilidade e indisponibilidade, além de os consagrarem como valores absolutos. Assim é que referidos direitos, positivados ao longo do artigo $5^{\circ}$, conduzem as ações positivas do Estado no âmbito Social privilegiando a Liberdade como meio a alcançá-1o ${ }^{13}$. Neste ponto cumpre assinalar que PASOLD ${ }^{14}$ defende a concepção de que os direitos sociais e coletivos são igualmente considerados Direitos Fundamentais, e que esta abrangência faz distinguir a passagem do Estado Contemporâneo para o Estado Moderno.

Pois bem.

Nos regimes democráticos o respeito e a garantia dos Direitos Humanos constituem a base da Igualdade jurídica e tornam possíveis o Reconhecimento dos Direitos das minorias no sentido da participação ativa no governo, com a garantia de "poderem se opor quando entenderem que o mesmo se afasta do reto caminho que leva à promoção do bem comum"15. Assim é que a Declaração Universal dos Direitos Humanos da Organização das Nações Unidas, de 1948, reconhece a Democracia enquanto regime ideal e a necessidade de assegurar dignidade como condição para o exercício da Liberdade e realização da Justiça. A sua proclamação liga-se à ideia de que o Reconhecimento que consta no texto independe da vontade de Governos ou Estados, tratando-se de Direito Fundamental inerente à condição Humana. Consequentemente, o Estado Contemporâneo ${ }^{16}$ para manter-se Democrático, deverá atuar e agir em prol de "toda a Sociedade", possuindo, deste modo, uma função social, constituindo a Liberdade e a Igualdade instrumentos para a efetivação da Justiça Social $^{17}$.

\footnotetext{
${ }^{13}$ ROSA, Alexandre Morais da. Crítica ao Discurso da Law and Economics: Exceção Econômica no Direito.In: ROSA, Alexandre Morais da e LINHARES, José Manuel Aroso. Diálogos com Law \& Economics. p.19

${ }_{14}$ PASOLD, Cesar Luiz. Função Social do Estado Contemporâneo.4 ed. rev. amp. Itajaí/SC: Univali, 2013.ebookhttp://siaiapp28.univali.br/LstFree.aspx.Acesso em 12 de janeiro de 2019. p.32

${ }^{15}$ ROSA, Alexandre Morais da. Crítica ao Discurso da Law and Economics: Exceção Econômica no Direito.In: ROSA, Alexandre Morais da e LINHARES, José Manuel Aroso. Diálogos com Law \& Economics. p.46; 47

${ }^{16}$ PASOLD, Cesar Luiz. Função Social do Estado Contemporâneo. 4 ed. rev. amp. Itajaí/SC: Univali, 2013. ebook http://siaiapp28.univali.br/LstFree.aspx. Acesso em 12 de janeiro de 2019. Pasold explica que o nascimento do Estado Contemporâneo se dá com a Constituição Mexicana de 1917, confirmando-se logo em seguida em 1919 com a Constituição Alemã de Weimar. A fim de aprofundar-se no conceito e elementos remeto o leitor à leitura do livro Estado contemporâneo, conforme especificações acima

${ }^{17}$ GOULART, Clovis de Souto. Formas e Sistemas de Governo. Porto Alegre/Fpolis: Sérgio Antônio Fabris Editor/CPGD-UFSC, 1995, p.16
} 
Entretanto, para a realização desta deve-se buscar uma Igualdade concreta, material, em que cada ser humano possa usar sua Igualdade de forma livre:

Com esse critério, justiça não significa que eu seja igual a você, mas que eu seja igual a você na possibilidade de exercitar a própria personalidade. De tal maneira, a igualdade abstrata se faz concreta na liberdade ${ }^{18}$.

Para a garantia da Igualdade é indispensável o compromisso com a Liberdade, civil e política, mínimo condicionante para a realização da cidadania que só se tornará possível como Reconhecimento de todos, sem distinção de Sexo, Gênero, Raça e Etnia, ao exercício dos Direitos e Liberdades Individuais. Estas diferenças deverão ser superadas através do, e com o apoio, no Estado.

Os movimentos feministas e a teoria da Justiça de Nancy FRASER reivindicam uma Igualdade baseada no valor de vivências, ou seja, uma Igualdade na diferença que possibilite a "livre expressão das individualidades, não a que aprisiona indivíduos e grupos em posições estereotipadas"19.

A recusa à universalização do masculino (ou do ocidental), com a valorização da diferença, é importante para evitar a aceitação acrítica de um conjunto de valores que está, ele próprio, vinculado às relações de dominação. [...] Ao lado da redistribuição, impõem-se a necessidade de conhecimento do valor de modo de vida diversos ${ }^{20}$.

Igualdade significa, então, o Reconhecimento da individualidade feminina, da possibilidade de livremente exercer essa particularidade. Liberdade de, e na, escolha de comportamentos.

PASOLD traça o seguinte conceito jurídico e político de liberdade:

Liberdade é a condição de sensibilidade, racionalidade e acessibilidade exercida pelo Homem quanto a alternativas. Portanto, fundamentalmente, a Liberdade é, nesta proposição, uma condição exercida frente a alternativas ${ }^{21}$.

\footnotetext{
${ }^{18}$ PASOLD, Cesar Luiz. Função Social do Estado Contemporâneo. 4 ed. rev. amp. Itajaí/SC: Univali, 2013. ebookhttp://siaiapp28.univali.br/LstFree.aspx.p. 42

${ }^{19}$ MIGUEL, Luis Felipe e BIROLI, Flávia. Feminismo e Política. São Paulo: Boitempo, 2014. p. 77

${ }^{20}$ 1MIGUEL, Luis Felipe e BIROLI, Flávia. Feminismo e Política. São Paulo: Boitempo, 2014. p. 73

${ }^{21}$ 2PASOLD, Cesar Luiz. Função Social do Estado Contemporâneo. 4 ed. rev. amp. Itajaí/SC: Univali, 2013. ebook http://siaiapp28.univali.br/LstFree.aspx.p. 40
} 
Nesse contexto é que as Ações Afirmativas se revelam importante instrumento de intervenção na dinâmica social com o escopo de corrigir injustiças cometidas contra determinados grupos.

Renata VILAS-BOAS conceitua Ação Afirmativa como medidas excepcionais adotada pelo Estado “de forma compulsória ou espontânea, com o propósito específico de eliminar desigualdades que foram acumuladas no decorrer da história da sociedade"22.

Flávia PIOVESAN ${ }^{23}$ assevera que as Ações Afirmativas são instrumentos de enfrentamento da injustiça Social e cultural que surgem para aliviar e remediar as condições resultantes de um passado de discriminação. Referindo-se à discriminação pela raça, PIOVESAN expõe:

Sob a perspectiva dos direitos humanos, as ações afirmativas em prol da população afrodescendentes surgem tanto como um instrumento capaz de enfrentar a injustiça social e econômica (traduzindo o direito à redistribuição), como também como um instrumento capaz de enfrentar a injustiça cultural (traduzindo o direito ao reconhecimento $)^{24}$.

As ações afirmativas, com suporte constitucional no artigo $3^{\circ}$, inciso IV, constituem um objetivo fundamental à promoção do desenvolvimento e superação de discriminações de toda sorte ${ }^{25}$.

Assim é que o Estado Contemporâneo tem o dever de programar e apoiar ações afirmativas, efetivando-as ${ }^{26}$.

No mesmo sentido, Daniel Hachem ensina que o Direito Constitucional, anterior a

\footnotetext{
${ }^{22}$ VILAS-BOAS, Renata Malta. Ações Afirmativas e princípio da igualdade. Rio de Janeiro. América Jurídica, 2003, p. 12.

${ }^{23}$ PIOVESAN, Flávia. Igualdade, diferença e direitos humanos: perspectivas global e regional. In: LEITE, George Salomão; SARLET, Ingo Wolfgang (Coord.) Direitos Fundamentais e Estado Constitucional: Estudos em homenagem a J.J. Gomes Canotilho. São Paulo: Revista dos Tribunais, 2009, p. 299

${ }^{24}$ PIOVESAN, Flávia. Igualdade, diferença e direitos humanos: perspectivas global e regional. In: LEITE, George Salomão; SARLET, Ingo Wolfgang (Coord.) Direitos Fundamentais e Estado Constitucional: Estudos em homenagem a J.J. Gomes Canotilho. São Paulo: Revista dos Tribunais, 2009, p. 299

${ }^{25}$ CRUZ, Álvaro Ricardo de Souza. O Direito à Diferença. As ações afirmativas como mecanismo de inclusão social de mulheres, negros, homossexuais e pessoas portadoras de deficiência. 3 ed. rev. Amp. atual. Belo Horizonte: Arraes, 2009. p. 163

${ }^{26}$ PASOLD, Cesar Luiz. Função Social do Estado Contemporâneo. 4 ed. rev. amp. Itajaí/SC: Univali, 2013. ebook http://siaiapp28.univali.br/LstFree.aspx.p. 57
} 
1988, estava atrelado a uma perspectiva autoritária e que não possuía força normativa, tratando-se de uma espécie de Direito Constitucional formal.

A partir de 1988 operou-se uma grande revolução no Direito Público nacional que atribuiu supremacia à Constituição, conferindo materialidade a todos os seus $\operatorname{comandos}^{27}$. A Constituição estabeleceu a Igualdade não só como um Princípio do Estado de Direito, mas, de um Estado Social $^{28}$, abrindo "espaço para um tratamento diferenciado que possibilite a implantação da Igualdade material" ${ }^{29}$, de discriminações positivas, concluindo que não é todo tratamento desigual que se converte inconstitucional.

Mais uma vez cumpre lembrar que a lógica formal do conceito de Igualdade é característica da primeira fase de proteção dos Direitos Humanos, que era marcado pela tônica da proteção geral.

Posteriormente, ao seu lado surge o direito à diferença e a possibilidade de distinguir três vertentes da Igualdade, quais sejam (i) Igualdade Formal, (ii) Igualdade Material correspondente à ideia de Justiça Social e Distributiva e (iii) Igualdade Material, correspondente ao ideal de Justiça enquanto reconhecimento de identidades ${ }^{30}$.

É justamente neste aspecto que o caráter bidimensional de Justiça formulado por Nancy FRASER vai ao encontro da Constituição da República de 1988.

Formada pela Igualdade Material, baseada na distribuição, somada ao Reconhecimento, tem-se o direito à diferença que conduz a uma condição igualitária e emancipatória. Constituem-se a essência dos Direitos Humanos "em sua dupla vocação em prol da afirmação, da dignidade e da prevenção do sofrimento humano"31.

A Justiça Social em um Estado Democrático se dará pelo alcance da igualdade e da

\footnotetext{
27 HACHEM, Daniel Wunder. A maximização dos direitos fundamentais econômicos e sociais pela via administrativa e a promoção do desenvolvimento. Revista Direitos Fundamentais \& Democracia (UniBrasil), v. 13, n. 13, Curitiba, UniBrasil, p. 340-399, jan./jul. 2013. p. 346

${ }^{28}$ MALISKA, Marcos Augusto. Análise da constitucionalidade das cotas para negros em universidade públicas. In: DUARTE, Evandro Charles Piza; BERTÚLIO, Dora Lúcia de Lima; SILVA, Paulo Vinícius Baptista da (Coord.). Cotas raciais no ensino superior: entre o jurídico e o político. Curitiba: Juruá, 2008. p.65

${ }^{29}$ PEIXINHO, Manoel Messias. GUANABARA, Ricardo. O sistema de cotas raciais e o principio constitucional da isonomia: um estudo sobre a cidadania, a igualdade e as ações afirmativas. XVCongresso $\begin{array}{llllll}\text { Nacional do } & \text { CONPEDI/UEA } & - & \text { Manaus. } & 2006 & \text { Disponível }\end{array}$ em:http://www.conpedi.org.br/manaus/arquivos/anais/manaus/direito_humano_td_manoel_pe ixinho_e_ricardo_gua abara.pdf.p. 7.

${ }^{30}$ PIOVESAN, Flávia. Igualdade, diferença e direitos humanos: perspectivas global e regional. In: LEITE, George Salomão; SARLET, Ingo Wolfgang (Coord.) Direitos Fundamentais e Estado Constitucional: Estudos em homenagem a J.J. Gomes Canotilho. São Paulo: Revista dos Tribunais, 2009, p. 304

${ }^{31}$ PIOVESAN, Flávia. Igualdade, diferença e direitos humanos: perspectivas global e regional. In: LEITE, George Salomão; SARLET, Ingo Wolfgang (Coord.) Direitos Fundamentais e Estado Constitucional: Estudos em homenagem a J.J. Gomes Canotilho. São Paulo: Revista dos Tribunais, 2009, p. 306
} 
liberdade de gênero. Daí a importância dos movimentos feministas, pois que representam um movimento político de natureza jurídica ao passo que almeja a igualdade e a inclusão sociais $^{32}$.

O Direito deve, assim, corresponder às expectativas sociais, e estar de olhos atentos às mudanças de paradigmas, das novas concepções de vida, de novos valores, de novos bens a serem tutelados/reconhecidos. Cumpre (re)aproximar a norma desses novos ideários axiológicos de uma sociedade multifacetada.

\section{AÇÕES AFIRMATIVAS COMO INSTRUMENTOS À EFETIVAÇÃO DA IGUALDADE MATERIAL DA MULHER.}

$\mathrm{O}$ interesse em superar a discriminação de gênero e efetivar os princípios constitucionais da igualdade, liberdade e da justiça social, se dá em razão de ter-se vivenciado uma longa história de opressão feminina. Nesse sentido, citam-se dois exemplos de instrumentos legais que visam atender à demanda por inclusão e visibilidade social da mulher na sociedade brasileira.

\subsection{Lei 11.340/2006"33: "Lei Maria da Penha"}

Atendendo aos ditames Constitucionais no que toca à proteção à família, ao combate às formas de violências no âmbito doméstico e familiar, dando efetividade aos documentos internacionais de proteção às Mulheres, desde a Convenção da $\mathrm{ONU}^{34}$ até as Regras de

\footnotetext{
${ }^{32}$ GUERRA FILHO, Willis Santiago e CARNO, Henrique Garbellini. Teoria política do direito: a expansão política do direito. 2a ed. São Paulo: RT, 2013. p. 8

${ }^{33}$ BRASIL. Lein ${ }^{\circ} 11.340 / 2006$, de 07 de agosto de 2006. Cria mecanismos para coibir a violência doméstica e familiar contra a mulher, nos termos do $§ 8$ o do art. 226 da Constituição Federal, da Convenção sobre a Eliminação de Todas as Formas de Discriminação contra as Mulheres e da Convenção Interamericana para Prevenir, Punir e Erradicar a Violência contra a Mulher; dispõe sobre a criação dos Juizados de Violência Doméstica e Familiar contra a Mulher; altera o Código de Processo Penal, o Código Penal e a Lei de Execução Penal; e dá outras providências. Diário Oficial da República Federativa do Brasil, Brasília, DF, 08 de ago. 2006. Disponível em:http://www.planalto.gov.br/ccivil_03/_Ato2004-2006/2006/Lei/L11340.htm. Acesso em 11 de jan.2019

${ }^{34}$ Convenção sobre a eliminação de todas as formas de discriminação contra a mulher de 1979. Ratificada pelo Brasil em 01.02.1984. Disponível em: Acesso em:20 dejan.de2019.
} 
Beijing $1995^{35}$, foi editada e promulgada a Lei11.340/06.

Conhecida como Lei Maria da Penha, tem, por finalidade, criar mecanismos para reprimir e prevenir a violência doméstica e familiar contra a Mulher, estabelecendo, conforme o art. $8^{\circ}$, "um conjunto articulado de ações da União, dos Estados, do Distrito Federal e dos Municípios e de ações não-governamentais"36.

A Lei considera violência aquela relacionada a qualquer ato ou omissão praticada no âmbito doméstico e familiar, que atente contra a sexualidade, vida, Liberdade, patrimônio, integridade física e moral da Mulher. Adverte Couto ${ }^{37}$ que a Lei declara alguns Direitos das Mulheres o que, por sua vez, atende à consolidação da Democracia e do Reconhecimento das demandas particulares de grupos específicos. Além disso, compõe um fenômeno da forma com que se enxerga a violência, que antes somente encontrava seu locus na segurança pública e hoje acha guarida também em temáticas relacionadas a Direitos Humanos $^{38}$.

A Lei assegura de forma ampla a assistência, o atendimento à Mulher em situação de violência, propõe medidas protetivas de urgência, cria Delégacias especializadas e o Juizado de violência Doméstica e Familiar contra a Mulher.

A positivação de uma Lei com normas que diferencia a violência feminina daquela que atinge homens pode significar "um passo para as assimetrias que geram as agressões e para o empoderamento feminino na busca por uma vida sem violência"39.

A Lei 11.340/06 representa um dos mais importantes documentos no combate à violência contra a Mulher. O Direito Penal chama para si a legitimidade de atuar nesse conflito, contudo, analisar sua efetividade e seus contornos específicos é assunto que extrapola o objetivo do presente artigo.

\footnotetext{
${ }^{35}$ Regras Mínimas das Nações Unidas para a Administração da Justiça, da Infância e da Juventude. Regras de Beijing. Disponível em. Acessoem:11de jan.2019.

${ }^{36}$ BRASIL. Lein ${ }^{\circ} 11.340 / 2006$, de 07 de agosto de 2006.Cria mecanismos para coibir a violência doméstica e familiar contra a mulher, nos termos do $\S 8$ o do art. 226 da Constituição Federal, da Convenção sobre a Eliminação de Todas as Formas de Discriminação contra as Mulheres e da Convenção Interamericana para Prevenir, Punir e Erradicar a Violência contra a Mulher; dispõe sobre a criação dos Juizados de Violência Doméstica e Familiar contra a Mulher; altera o Código de Processo Penal, o Código Penal e a Lei de Execução Penal; e dá outras providências. Diário Oficial da República Federativa do Brasil, Brasília, DF, 08 de ago. 2006. Disponível em:http://www.planalto.gov.br/ccivil_03/_Ato2004-2006/2006/Lei/L11340.htm. Acesso em 11 dejan.2019.

${ }^{37}$ COUTO, Maria Claudia Girotto do. Lei Maria da Penha e Princípio da Subsidiariedade: Diálogo entre um direito penal mínimo de proteção contra a violência de gênero no Brasil. São Paulo: IBCCRIM, 2017.p.50 38 9COUTO, Maria Claudia Girotto do. Lei Maria da Penha e Princípio da Subsidiariedade: Diálogo entre um direito penal mínimo de proteção contra a violência de gênero no Brasil. São Paulo: IBCCRIM, 2017.p.50 ${ }^{39}$ COUTO, Maria Claudia Girotto do. Lei Maria da Penha e Princípio da Subsidiariedade: Diálogo entre um direito penal mínimo de proteção contra a violência de gênero no Brasil. São Paulo: IBCCRIM, 2017. p. 52
} 


\subsection{A Lei 9.504/97 ${ }^{40:}$ As Mulheres na Política}

A imposição de cotas em matéria eleitoral constitui-se num esforço para melhorar a participação feminina nos Parlamentos em todos os níveis da Federação. Constitui uma forma de se dar voz e representação femininas através da política. A ínfima participação das Mulheres nos espaços legislativos constitui um déficit democrático mundial, que inspirou o nascimento de políticas de cotas de gênero a fim de ampliar a representação feminina na política desde $1990^{41}$.

A "Conferência Mundial sobre a Mulher: Igualdade, Desenvolvimento e Paz" ${ }^{42}$, em Pequim, nos anos de 1995, firmou o compromisso com todos os países presentes, inclusive o Brasil, em se criar ações afirmativas para suprir a ausência das Mulheres nos processos decisórios como garantia da vigência da Democracia plena.

No Brasil, a deputada Marta Suplicy (PT/SP) propôs Projeto de Lei que previa uma cota mínima de 30\% para candidaturas de Mulheres. Referida proposta somente foi aceita com a redução para 20\%, sendo, então, aprovada a Lein $^{\circ} 9.100$, de 29 de setembro de 1995. Em 1997 a Lei recém promulgada sofreu nova alteração, então, com o advento da Lei 9.504/97, que se passou a prever percentual de no mínimo 30\% das vagas e o máximo de $70 \%$ para candidaturas de cada sexo. Em 2009, a Lei 12.034/09 alterou o art. 107 da Lei 9.504/97, substituindo a expressão "reserva" para "preencherá", tornando obrigatório o preenchimento das cotas de gênero na definição das candidaturas de cada partido político. A mesma Lei criou ainda, uma reserva de no mínimo10\% do tempo da propaganda partidária para incentivar a participação feminina na política, bem como a destinação de $5 \%$ do Fundo Partidário para a criação e manutenção de programas de promoção e difusão da participação política das Mulheres ${ }^{43}$.

\footnotetext{
${ }^{40}$ BRASIL. Lei ${ }^{\circ}$ 9.504/97, de 30 de setembro de 1997. Estabelece normas para as eleições. Diário Oficial da República Federativa do Brasil, Brasília, DF, 01 de out. 1997. Disponível em: Acesso em 11 de jan. 2019.

${ }^{41}$ MELO, Hildete Pereira de. A política de cotas para as mulheres no Brasil: importância e desafios para avançar! Disponível em: Acesso em 11 de jan. 2019.

${ }^{42}$ Disponível em: Acesso em 30 de jan. de 2019.

${ }^{43}$ MELO, Hildete Pereira de. A política de cotas para as mulheres no Brasil: importância e desafios para avançar! Disponível em:< http://www.generonumero.media/a-politica-de-cotaspara-as-mulheres-no-brasilimportancia-e-desafios-para-avancar/> Acesso: 11 de jan.de 2019
} 
Em 8 de setembro de 2015, as Congressistas colocaram em votação a paridade de gênero na representação parlamentar nacional, porém, o Senado Federal aprovou a Emenda Constitucional que implementa progressivamente cotas de legislatura de gênero no Brasil, na proporção de $10 \%, 12 \%$ e $16 \%$ para as legislaturas seguintes derrotando o pleito feminino ${ }^{44}$.

O Tribunal Superior Eleitoral, representado pela Ministra Rosa Weber, determinou que $30 \%$ do Fundo Especial Eleitoral destinam-se às campanhas de candidaturas de Mulheres $^{45}$.

Conforme exposto, a Lei 11.340/06 e Lei 9.504/95, ainda que com deficiências, representem avanços e inauguram um processo de mudança de paradigma na Sociedade que é a luta contra o preconceito e discriminação contra as Mulheres.

\section{CONSIDERAÇÕES FINAIS}

No Brasil, a luta pela quebra do paradigma discriminatório e a sua necessária justificação devem passar pela constatação de que a Sociedade brasileira sistematizou privilégios por questões de gênero ao longo da história.

O critério adotado pela Justiça de Gênero de Nancy FRASER perpassa a busca da Redistribuição e do Reconhecimento. Desta forma, as Ações Afirmativas de combate à discriminação de gênero devem ser analisadas partindo de uma necessária complexificação do fenômeno histórico e entendê-las como um fato social, psicológico, antropológico.

O fato é que da análise dos diversos instrumentos internacionais que versam sobre Direitos Humanos, constata-se que o exercício da cidadania somente será possível através da efetivação dos Princípios da Igualdade, Liberdade e da Justiça Social. Desta forma, ao reconhecer as profundas desigualdades geradas concretamente é que as Ações Afirmativas se revelam importante instrumento de intervenção na dinâmica social com o escopo corrigir injustiças e promover a paridade de Gênero.

A Constituição da República de 1988 atribuiu diretamente ao Estado o dever de

${ }^{44}$ SALGADO, Eneida Desiree; GUIMARÃES, Guilherme Athaides et MONTE-ALTO, Eric Vinicius Lopes Costa. Cotas de Gênero na Política: entre a história, as urnas e o Parlamento. Periódico do Núcleo de Estudos e Pesquisas sobre Gênero e Direito Centro de Ciências Jurídicas- Universidade Federal da Paraíba. v.4, n.3. 2015. p. 156-182. Disponível em: http://www.periodicos.ufpb.br/ojs/index.php/ged/article/view/25973. Acesso em 30 dejan.de2019.

45 TSE. Consulta n. 0600252-18.2018.6.00.0000. Relatora Rosa Weber. DJ: 23/05/2018. Disponível em: Acesso em 30 dejan.de2019. 
atuação no sentido da promoção dos Direitos Fundamentais, econômicos e sociais, bem como conferiu materialidade a todos os seus Princípios, sendo imperativo deste Estado superar o aspecto meramente formal.

O caráter bidimensional da Justiça, formado pela Igualdade Material, baseado na Distribuição, somado ao Reconhecimento da identidade, constitui-se em verdadeiro direito à diferença que conduz a uma condição igualitária e emancipatória.

Essa é a essência dos Direitos Humanos, eliminar as desigualdades reconhecendo no outro a diferença e conferindo-lhe oportunidade para que sua condição pessoal possa ser exercida.

\section{REFERÊNCIAS BIBLIOGRÁFICAS}

BRASIL. Lei no 9.504/97, de 30 de setembro de 1997. Estabelece normas para as eleições. Diário Oficial da República Federativa do Brasil,Brasília, DF, 01 de out. 1997. Disponível em:http://www.planalto.gov.br/ccivil_03/_Ato2004-2006/2006/Lei/L11340.htm. Acesso em 11 de jan. 2019.

BRASIL. Lein ${ }^{\circ} 11.340 / 2006$, de 07 de agosto de 2006. Cria mecanismos para coibir a violência doméstica e familiar contra a mulher, nos termos do $\$ 8^{\mathrm{O}}$-doart. 226 da Constituição Federal, da Convenção sobre a Eliminação de Todas as Formas de Discriminação contra as Mulheres e da Convenção Interamericana para Prevenir, Punir e Erradicar a Violência contra a Mulher; dispõe sobre a criação dos Juizados de Violência Doméstica e Familiar contra a Mulher; altera o Código de Processo Penal,o Código Penal e a Lei de Execução Penal; e dá outras providências. Diário Oficial da República Federativa do Brasil, Brasília, DF, 08 de ago. 2006. Disponível em:http://www.planalto.gov.br/ccivil_03/_Ato20042006/2006/Lei/L11340.htm.Acesso em 11 dejan.2019.

COUTO, Maria Claudia Girotto do. Lei Maria da Penha e Princípio da Subsidiariedade:

Diálogo entre um direito penal mínimo de proteção contra a violência de gênero no Brasil. São Paulo: IBCCRIM,2017. 
CRUZ, Álvaro Ricardo de Souza. O Direito à Diferença. As ações afirmativas como mecanismo de inclusão social de mulheres, negros, homossexuais e pessoas portadoras de deficiência. 3 ed. rev. amp. Atual. Belo Horizonte: Arraes, 2009.

DA SILVA, Salete Maria et WRIGHT, Sonia Jay. Uma reflexão feminista sobre o conceito de justiça de gênero. In: Revista de teorias da justiça, da decisão e da argumentação jurídica.v. 2; n. 1; p. 1-27, jan-jun. 2016.

FRASER, Nancy. La política feminista em la era del reconocimiento: um enfoque bidimensional de la justicia de gênero. Traducción: Marta Postigo Asenjo.In:Arenal, 19:2; Julio-deciembre 2012. Título original: Feminists Politics in the Age os Recognition: atwodimensional approach to gender justice.

GOULART, Clovis de Souto. Formas e Sistemas de Governo. Porto Alegre/Fpolis: Sérgio Antônio Fabris Editor/CPGD-UFSC, 1995.

GUERRA FILHO, Willis Santiago et CARNO, Henrique Garbellini. Teoria política do direito: a expansão política do direito. $2^{\mathrm{a}}$ ed. São Paulo: RT, 2013.

HACHEM, Daniel Wunder. A maximização dos direitos fundamentais econômicos e sociais pela via administrativa e a promoção do desenvolvimento. In: Revista Direitos Fundamentais \& Democracia (UniBrasil), v.13, n.13, p. 340-399, Curitiba, UniBrasil, jan./jul.2013.

HELLER, Hermann. Teoria do Estado. Tradução de Lycurgo Gomes da Motta. São Paulo: Mestre Jou,1968. Título original :Staatslehre.

MELO, Hildete Pereira de. A política de cotas para as mulheres no Brasil:importância e desafios para avançar! Disponível em:http://www.generonumero.media/a-politica-de-cotaspara-as-mulheres-no-brasil-importancia-e-desafios-para-avancar/Acesso: 11 de jan. de 2019.

MALISKA, Marcos Augusto. Análise da constitucionalidade das cotas para negros em universidade públicas. In: DUARTE, Evandro Charles Piza; BERTÚLIO, Dora Lúcia de 
Lima; SILVA, Paulo Vinícius Baptista da (Coord.). Cotas raciais no ensino superior: entre o jurídico e o político. Curitiba: Juruá, 2008.

MIGUEL, Luis Felipe e BIROLI, Flávia. Feminismo e Política. São Paulo: Boitempo, 2014.

PASOLD, Cesar Luiz. Função Social do Estado Contemporâneo. 4 ed. rev. amp. Itajaí/SC: Univali, 2013.ebook http://siaiapp28.univali.br/LstFree.aspx.Acesso: 10 de jan. de 2019.

PASOLD, Cesar Luiz. Metodologia da Pesquisa Jurídica: Teoria e Prática. 14 ed. rev. atual. e amp. Florianópolis: Emais, 2018.

PEIXINHO, Manoel Messias. GUANABARA, Ricardo. O sistema de cotas raciais e o princípio constitucional da isonomia: um estudo sobre a cidadania, a igualdade e as ações afirmativas. XV Congresso Nacional do CONPEDI/UEA - Manaus. 2006 Disponível em:http://www.conpedi.org.br/manaus/arquivos/anais/manaus/direito_humano_td_manoel_pe i xinho_e_ricardo_gua abara.pdfAcesso em: 14 de jan. 2019.

PIOVESAN, Flávia. Igualdade, diferença e direitos humanos: perspectivas global e regional. In: LEITE, George Salomão; SARLET, Ingo Wolfgang (Coord.) Direitos Fundamentais e Estado Constitucional: Estudos em homenagem a J.J. Gomes Canotilho. São Paulo: Revista dos Tribunais, 2009.

ROSA, Alexandre Morais da et LINHARES, José Manuel Aroso. Diálogos com Law \& Economics. São Paulo: Lumen Juris, 2009.

SALGADO, Eneida Desiree; GUIMARÃES, Guilherme Athaides et MONTE-ALTO, Eric Vinicius Lopes Costa. Cotas de Gênero na Política: entre a história, as urnas e o Parlamento. Periódico do Núcleo de Estudos e Pesquisas sobre Gênero e Direito Centro de Ciências Jurídicas- Universidade Federal da Paraíba. v.4, n.3. 2015. p. 156182. Disponível em:http://www.periodicos.ufpb.br/ojs/index.php/ged/article/view/25973. Acesso em 30 dejan.de2019. 
TSE. Consulta n. 0600252-18.2018.6.00.0000. Relatora Rosa Weber. DJ: 23/05/2018.

Disponível em: 〈https://www.conjur.com.br/dl/voto-rosa-weber-consulta-publica.pdf>. Acessoem30 dejan.de2019.

VILAS-BOAS, Renata Malta. Ações Afirmativas e princípio da igualdade. Rio de Janeiro. América Jurídica, 2003. 